\title{
Heterologous expression and antitumor activity analysis of syringolin from Pseudomonas syringae pv. syringae B728a
}

Fan Huang ${ }^{\dagger}$, Jianli Tang ${ }^{\dagger}$, Lian He, Xuezhi Ding, Shaoya Huang, Youming Zhang, Yunjun Sun and Liqiu Xia *i)

\begin{abstract}
Background: Syringolin, synthesized by a mixed non-ribosomal peptide synthetase/polyketide synthetase in Pseudomonas syringae pv. syringae (PSS) B728a, is a novel eukaryotic proteasome inhibitor. Meanwhile, directly modifying large fragments in the PKS/NRPS gene cluster through traditional DNA engineering techniques is very difficult. In this study, we directly cloned the syl gene cluster from Pss B301D-R via Red/ET recombineering to effectively express syringolin in heterologous hosts.
\end{abstract}

Results: A 22 kb genomic fragment containing the sy/A-sylE gene cluster was cloned into the pASK vector, and the obtained recombinant plasmid was transferred into Streptomyces coelicolor and Streptomyces lividans for the heterologous expression of syringolin. Transcriptional levels of recombinant syl gene in S. coelicolor M145 and S. Iividans TK24 were evaluated via RT-PCR and the production of syringolin compounds was detected via LC-MS analysis. The extracts of the engineered bacteria showed cytotoxic activity to B16, 4T1, Meth-A, and HeLa tumor cells. It is noteworthy that the syringolin displayed anticancer activity against C57BL/6 mice with B16 murine melanoma tumor cells. Together, our results herein demonstrate the potential of syrinolin as effective antitumor agent that can treat various cancers without apparent adverse effects.

Conclusions: This present study is the first to report the heterologous expression of the entire syl gene cluster in Streptomyces strains and the successful expression of syringolin in both S. coelicolor M145 and S. lividans TK24. Syringolin derivatives demonstrated high cytotoxicity in vitro and in vivo. Hence, this paper provided an important foundation for the discovery and production of new antitumor compounds.

Keywords: Antitumor, Heterologous expression, Red/ET recombineering, Syringolin, Streptomyces

\section{Background}

Pseudomonas syringae pv. syringae (Pss) is a foliar bacterial pathogen that causes brown spot disease in snap beans (Phaseolus vulgaris L.) $[1,2]$ and produces a novel polyketide complex, known as syringolin [3, 4]. Application of syringolin at micromolar concentrations onto rice plants can induce resistance against rice blast fungus. However, Pss mutants are incapable of syringolin

\footnotetext{
*Correspondence: xialq@hunnu.edu.cn

${ }^{\dagger}$ Fan Huang and Jianli Tang contributed equally to this work

Hunan Provincial Key Laboratory of Microbial Molecular Biology, State Key Laboratory of Developmental Biology of Freshwater Fish, College of Life Science, Hunan Normal University, Changsha 410081, People's Republic of China
}

biosynthesis and induce defense reactions and resistance, revealing its marginal therapeutic activity against systemic fungal infections [5, 6]. Recently, syringolin has shown potent in vivo antitumor activity against neuroblastoma, ovarian, and leukemic cancer cells [7]. Such specificity of syringolin inhibits all three catalytic activities of eukaryotic proteasomes $[8,9]$. The proteasome acting during protein degradation has been known as a biological target for the clinic treatment lately $[10,11]$. Syringolin was confirmed as the notable peptide moiety in a 12-membered macrolactam ring structure, which also has two double bonds with (E)-configuration and an unusual urea moiety [12] (Fig. 1). The special chain reversal by ureido linkage was also present in natural products, 


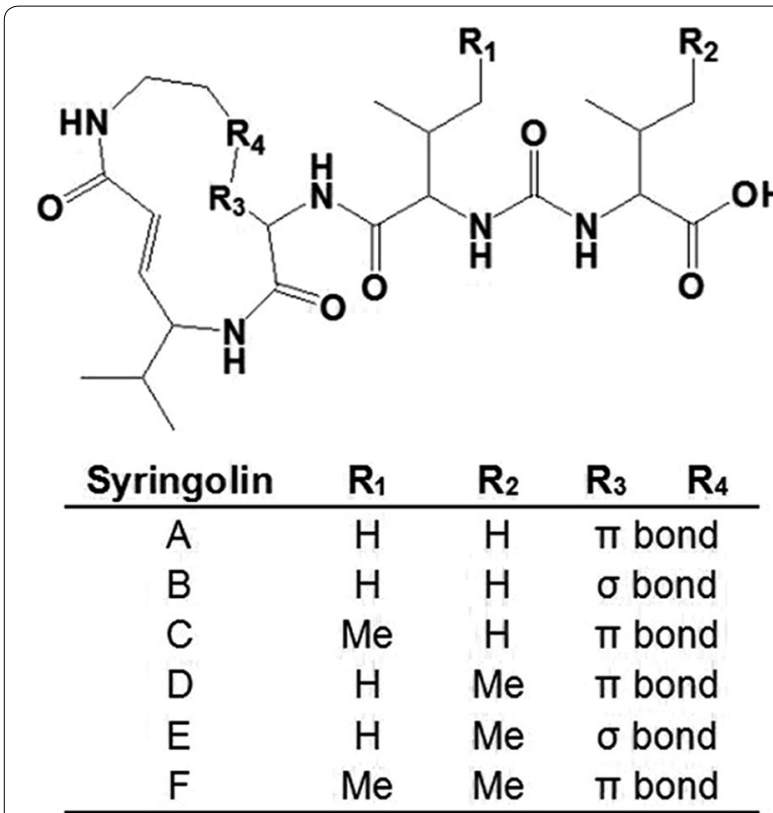

Fig. 1 The structure of syringolin. The ring structure consists of two non-proteinogenic amino acids, namely, 3,4-dehydrolysine and 5-methyl-4-amino-2-hexenoic acid. The a-amino group of the latter attaches to valine through a peptide bond, which in turn, is linked to a second valine residue via an unusual ureido group anabaenopeptins [13], brunsvicamides [14], pacidomycins [15], mureidomycins [16], and napsamycins [17]. Syringolin is a bioactive member of the syrbactins family, which also includes glidobactins and cepafungins. $\mathrm{N}$-acylation dramatically influences the inhibitory activity of syringolin to proteasome [18]. As a promising anticancer agent, syringolin has great antitumor activity in inhibiting growth and inducing apoptosis of neuroblastoma, ovarian cancer cells, and other tumor cells $[19,20]$.

The syringolin biosynthetic gene cluster spanned $22 \mathrm{~kb}$ in length and included five open reading frames (sylA$s y l E$ ). The NRPS module sequence in the chromosome generally determines the amino acid sequence of the peptide product [21] (Fig. 2) where sylA is a putative transcription activator; sylB hypothetically encodes the lysine reductase; $s y l C$ encodes a module predicted for valine activation [22]; sylD codes two typical NRPS modules that activate lysine (or dehydrolysine) and 5-methyl4-amino-2-hexenoic acid (or its precursor); and sylE possibly serves as an exporter [23].

The genetic manipulation for PKS/NRPS gene cluster is difficult to perform using conventional DNA engineering methods because of their large sizes (spanning $10-100 \mathrm{~kb})$. Red/ET recombineering [17, 18], which is

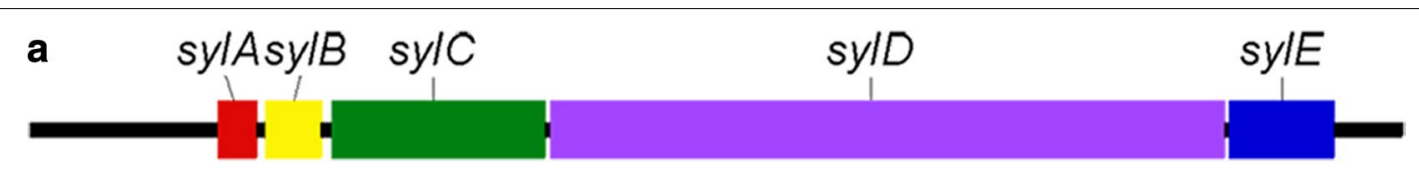

b sylC

sylD

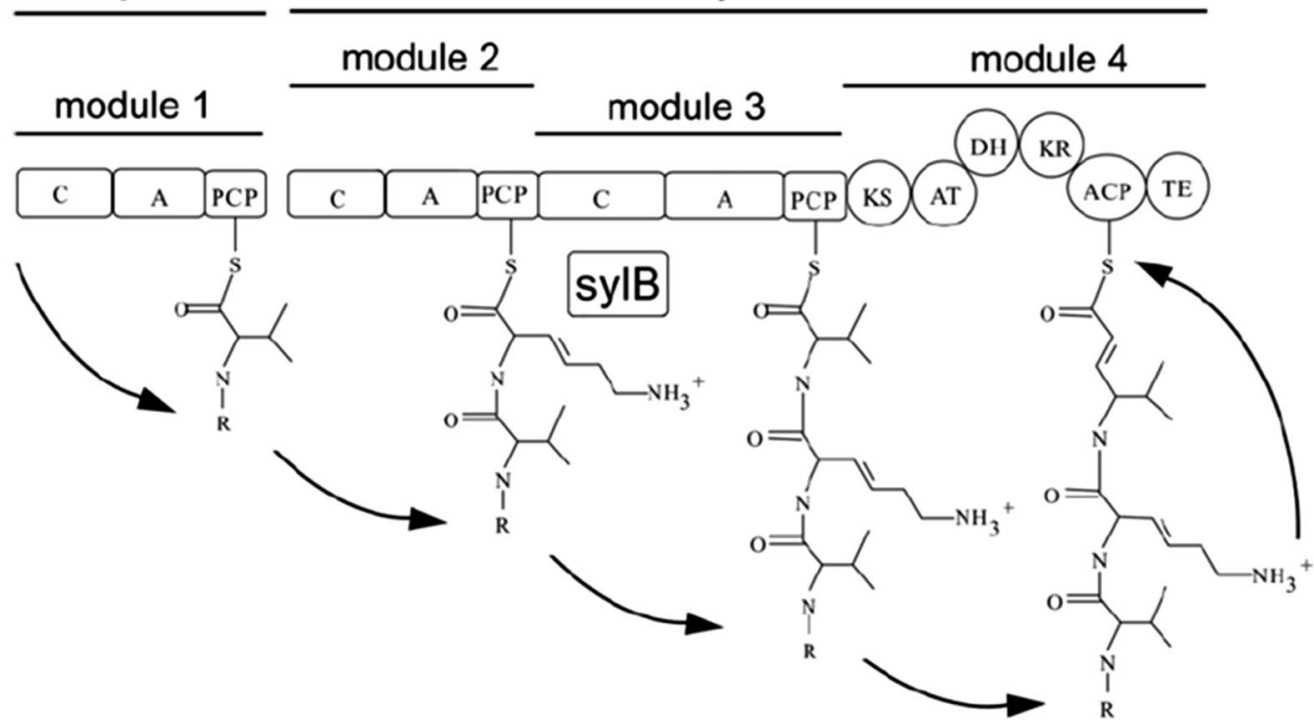

Fig. 2 Arrangement of syl gene cluster and biosynthesis modules. Colored boxes represent open reading frames (ORFs) of syl gene cluster (a). Boxes labeled as C, A, and PCP represent condensation, activation, and peptide carrier protein domains of synthetase modules encoded by sylC and sylD, respectively. Circles denote putative $\beta$-ketoacyl synthetase (KS), acyl transferase (AT), dehydratase (DH), $\beta$-ketoreductase (KR), acyl carrier protein (ACP), and thioesterase (TE) domains of the polyketide-like module, which is also encoded by sylD (b) 
independent of restriction site location and DNA fragment size, has extraordinarily advanced the field of genetic manipulation by omitting many steps in standard restriction/ligation. Direct cloning was recently established based on full-length Rac prophage protein, RecE, and its partner RecT-mediated linear plus linear homologous recombination (LLHR) [24]. This efficient cloning approach, when applied to direct cloning of large gene clusters from genomic DNA, might greatly promote the course of genome mining and combinatorial biosynthesis of PKS/NRPS compounds.

In this study, we report the direct cloning of an intact syl gene cluster from the genomic DNA of Pss B301D-R and replaced its native promoter with $\mathrm{P}_{\text {snpA }}$, a strong native promoter in Streptomyces, to actively produce the syl gene in heterologous hosts. We analyze the bioactivity of the recombinant products by treatment of several cancer cell lines and tumor model in mice to provide a suitable protocol for syringolin production and clinical application in the future.

\section{Methods}

\section{Bacterial strains and culturing conditions}

Various E. coli strains were cultured at $37{ }^{\circ} \mathrm{C}$ in LuriaBertani (LB) medium supplemented with antibiotics. Kanamycin $(30 \mu \mathrm{g} / \mathrm{mL}$; Sigma Chemical Co., St. Louis, Mo.), blasticidin $S(50 \mu \mathrm{g} / \mathrm{mL})$, tetracycline $(5 \mu \mathrm{g} / \mathrm{mL})$, and ampicillin $(100 \mu \mathrm{g} / \mathrm{mL})$ were added to the growth media as required. Heterologous hosts, S. lividans TK24 and S. coelicolor M145 strains, were grown at $30{ }^{\circ} \mathrm{C}$ on M2 (0.4\% glucose, $1 \%$ malt extract, $0.4 \%$ yeast extract, and $0.1 \% \mathrm{CaCO}_{3}$ ) or in TSB medium (tryptic soy broth (Oxoid), $30 \mathrm{~g} / \mathrm{L}$ ) for metabolite analyses as previously reported [25]. MS-agar medium [14] was used to transfer the cosmids from E. coli into Streptomyces in accordance with the standard protocol [26]. Apramycin $(50 \mu \mathrm{g} / \mathrm{mL})$ and nalidixic acid $(25 \mu \mathrm{g} / \mathrm{mL})$ were supplemented in the medium whenever necessary.

\section{Recombineering}

All engineering used Red/ET recombination techniques as described previously [27, 28]. Red/ET-competent $E$. coli cells $(50 \mu \mathrm{L})$ were electroporated with $0.3 \mu \mathrm{g}$ of a linear fragment (either PCR product or fragment obtained from restriction). PCRs were performed with Phusion polymerase (New England Biolabs, GmbH, Frankfurt am Main, Germany). After electroporation, the selection of recombinants was carried out depending on antibioticresistant gene and examined by restriction analysis.

\section{Direct cloning of the syl gene cluster}

For direct cloning, genomic DNA from Pss B301DR (GenBank: AJ548826) was digested with restriction enzymes, Asc I and SnaB I, to release the syl gene cluster region. Nco I and BamH I digests of plasmid p15Adir [12], served as the PCR template. DNA Oligos used for generation of p15A-IR-Tpaes-BSD-oriT-IR backbone (Tpaes: MycoMar transposase gene; IR: inverted repeat; BSD: blasticidin S-resistant gene) were as follows: (sequence as homologous arm for recombineering is in lowercase)

\section{Syldir5: 5 -ttgcactctgttcgaactcccattccagcttttgtctgccg- gtgcttttttcatggccaaccgtatcaccgcgcaatgaaagtg}

Syldir3: 5 '-tgcggcgaagctttgcatgacccagtgcagtacgtccgggtccagcagatgccattcgcgacgcgccttgaccaccgtg ccgacacgcggccAAGCTTGACCTGTGAAGT GAAAAATG-3'.

PCR product and linear genomic DNA were cotransformed into recombineering proficient competent GBdir cells to obtain p15A-syl-IR-Tpaes-BSD-oriT-IR. Sequencing the syl gene used primers sylseq-up (5'-ccggcctacacgcattc sylA end) and sylseq-down (5'-agcaacctggatgtacgg $s y l E$ end).

\section{Engineering the syl gene cluster}

To obtain highly heterologous expression in Streptomyces strain, a strong promoter $\mathrm{P}_{\text {snpA }}$ was inserted in front of the syl gene in p15A-syl-IR-Tpaes-BSD-oriT-IR to form the p15A-syl-IR-Tpaes-BSD-oriT-IR construct. The $\mathrm{P}_{\text {snpA }}$-apra cassette (apra: apramycin-resistant gene) was prepared with Psnpsyl5 (5'-TTAATGATGTCTCGT TTAGATAAAAGTAAAGTGATTAACAGCGCATTA GCGCGCCTATCCTCCATGGTATAAATCG-3') and Psnpsyl3 (5'-GGAATTAATCATCTGGCCATTCGA TGGTGTCGGGTCATGTGAGCAAAAGGGAAGCCG CGGGAGTAATCCT-3').

\section{Conjugation into streptomyces}

The engineered $s y l$ gene cluster was introduced into the chromosome of Streptomyces strains by triparental mating using E. coli helper strain HB101 (pRK2013). The mating mixture was plated on MS agar medium and incubated at $30{ }^{\circ} \mathrm{C}$ for $18 \mathrm{~h}$. These plates were overlaid with $1 \mathrm{~mL}$ of water containing $500 \mu \mathrm{g}$ of nalidixic acid and $1 \mathrm{mg}$ of apramycin and incubated further for 5 days at $30{ }^{\circ} \mathrm{C}$. After two cycles of single-colony purification on selective plates, the ex-conjugants were tested by colony PCR (Taq-polymerase, Invitrogen) with the following primers below: 
sylC-checkF: 5'-ATGAGCACGCACCAGCACGC-3'; sylC-checkR: 5'-CATTCACCAACTGCCCTATC-3';

sylD-checkF: 5'-GGAGCAGACTTACGGTCAGA-3'; sylD-checkR: 5'-TAGCCAGCATATTTTCCAGC-3'; sylE-checkF: 5'-TGGCGTTGACACTTTATTCA-3'; sylE-checkR: 5'-CAACGTTACCCGCAAATATC-3'.

\section{RNA extraction and RT-PCR analysis}

Total RNA was extracted by the TRIzol $^{\circledR}$ (Invitrogen) method. The RNA quality was analyzed by absorbance measurement and formaldehyde-denatured agarose gel electrophoresis. RT-PCR of syl gene cluster was performed based on the previous protocol [29]. Control (RTminus) reaction including all components for RT-PCR except the reverse transcriptase enzyme excluded the presence of genomic DNA. The expression of $16 \mathrm{~S}$ rRNA gene from heterologous host served as a positive internal control. Reverse transcription reactions were conducted with the primers: sylB5 (5'-TGGCGCATGACCGATTGC GT-3'), sylB3 (5'-TCGGCATGCACGGGGACAAC-3'), sylC5 (5'-ACTGCCAATGGGAGCGCGAC-3'), sylC3 (5'-CAACTTACCCG GCAGCGGCA-3'), sylD5 (5'-ACT ATCGCGCTCGTGTCCAA-3'), sylD3 (5'-CAGCCC GATACCGTCAGAAA-3'), sylE5 (5'-AAAGCCTTG CGGCCGAGCAT-3'), sylE3 (5'-AACCAGGAGCAC GTCGCAGC-3'), 16SRNA-F (5'-CTACCTCAAGCA GATCGGCAAG-3'), and 16SRNA-R (5'-GATCAGGTC CAGGAACGCCATG-3').

\section{HPLC analysis and mass spectrometry of syringolin}

Recombinant Streptomyces strains were grown on an M2 medium for 7 days at $30{ }^{\circ} \mathrm{C}$. For the metabolite analyses, supernatant cultures were extracted with equal volumes of ethyl acetate after centrifugation and dried in a rotary evaporator. The extracts were then dissolved in methanol and filtered $(0.22 \mu \mathrm{m}$ pore size). LC-MS/MS experiments were performed on LTQ XL hybrid mass spectrometer (Thermo Fisher Scientific, USA) coupled to a Finnigan LC system (Thermo Fisher Scientific). The extracts were subjected and desalted online in a reverse-phase precolumn (C18 Pepmap column, LC Packings) and resolved on a nanoscale C18 Pepmap TM capillary column (LC Packings) at a flow rate of $0.4 \mathrm{~mL} / \mathrm{min}$ (solvent $\mathrm{A}=0.1 \%$ formic acid in $\mathrm{H}_{2} \mathrm{O}$; solvent $\mathrm{B}=$ acetonitrile and $0.1 \%$ formic acid; 0-15 min 95\% A and 5\% B to $95 \%$ B [linear gradient], followed by $5 \mathrm{~min} 5 \% \mathrm{~A}$ and $95 \% \mathrm{~B}$ ). Detection was carried out in positive ion model, auto MSn. Syringolins were identified by comparing the retention times and MS2 data identified from the original producer.

\section{Bioactivity assays}

Cell viability and death was determined by 3-(4,5-dimethyl-2-thiazolyl)-2,5-diphenyl-2H-tetrazolium bromide (MTT) assay for adherent B16, HeLa, 4T1, and MethA cells in 96-well plates as described [12, 25]. Cells were incubated with 10 or $20 \mu \mathrm{L}$ syringolin extracts from Streptomyces strains for 48-72 $\mathrm{h}$, and the optical density (OD) of each well was determined in an ELISA reader at $560 \mathrm{~nm}$.

In vivo therapeutic assessment was carried out using 4T1 breast tumor model and B16 melanoma tumor model as described previously [1]. SPF female BALB/c and $\mathrm{C} 57 \mathrm{BL} / 6$ mice, aged $6-8$ weeks old, were purchased from the SLRC Laboratory Animal Company in Hunan, China. Animals were bred and maintained in SPF conditions and were kept for at least 3 days before use. Tumors in the fourth mammary pads of female BALB/c mice were established with $1 \times 10^{5}$ 4T1 mouse breast tumor cells, and C57BL/6 mice were implanted with SC tumors by injecting with $1 \times 10^{5}$ B16 cells on the mid-right side. After the tumor volume reached $\sim 0.2 \mathrm{~cm}^{3}$, breast tumor model BALB/c mice were randomly assigned to seven groups, and C57BL/6 mice bearing B16 tumor were randomly assigned to four groups. Syringolin extracts were injected for every 2 days within a span of 10 days. Tumor weights were estimated using two-dimensional caliper measurements conducted thrice per week using the formula: tumor weight $(\mathrm{mg})=\left(\mathrm{a} \times \mathrm{b}^{2}\right) / 2$, where $\mathrm{a}$ and $\mathrm{b}$ are the tumor length and width in $\mathrm{mm}$, respectively. At a defined time, mice were sacrificed by cervical dislocation. However, moribund animals characterized by irregular respiration, tremors, absence of voluntary response to external stimuli, and coma were killed for humane reasons and considered as animals that died during survival experiments. All animal experiments were repeated thrice in this study. All animal experiments followed the National Institutes of Health Guide for the Care and Use of Laboratory Animals and obtained the approval from the Animal Ethics Committee of Hunan Normal University.

\section{Histology}

Primary tumors, liver, kidney, and spleen from tumorbearing and control mice were harvested and fixed in $10 \%$ buffered formalin. Standard hematoxylin and eosin (HE) staining procedures were employed for morphological assessment [30]. The paraffin embedded samples were cut into $5 \mu \mathrm{m}$ sections, and every twentieth section was stained and examined by microscopy. 


\section{Results and discussion}

\section{Direct cloning of intact sly gene cluster}

The syl gene cluster from Pss B301D-R was isolated through Red/ET direct cloning. Plasmid pAsk-amp-syl (Fig. 3a) was constructed after PCR amplification of the minimal replicon with 90-nucleotide homology arms at the start and end of the $s y l$ gene. Digestion with Pst and DNA sequencing revealed the presence of an intact syl gene. For successful integration into the chromosome and heterologous expression in Streptomyces strains, the resulting plasmid, p15A-Tpase-syl (Fig. 3b) was generated through triple recombination [31]. One fragment contained the BamH I/Xba I restriction enzyme sites of p15Adir while the second one employed from PCR introduces a new promoter, $\mathrm{P}_{\text {snpA }}$, a regulator snpR, and another IR sequence. BSD- and kanamycin-resistant colonies were cultured and verified by restriction analysis. This direct cloning method led to less mutations and much longer target DNA fragments than the approach achieved by PCR, because their cloning depends on the E. coli replication machinery and not on PCR, which is error-prone. Obviously, the technique is easier and faster than the standard method needed to establish and to screen the genomic DNA library.

The recombinant syl gene cluster was introduced and was integrated into Streptomyces strains and chromosome through a well-established E. coli: Streptomyces intergeneric conjugation protocol [32]. Syringolin compounds are synthesized by enzymatic actions of the $s y l B$, $s y l C$, and $s y l D$ gene products, and the generation and condensation of the ureido valine remained enigmatic. The modified $\mathrm{P}_{\text {snpa }}$ promoter with native transcriptionactive $s y l A$ gene proved the efficient expression of the $s y l$ gene cluster in Streptomyces heterologous hosts.
Identification gene transcriptional levels of syl gene cluster in heterologous expression hosts

Transcriptional levels of recombinant syl gene in S. coelicolor M145 and S. lividans TK24 were evaluated via RTPCR. Total RNA was extracted after fermentation for 24, $32,38,46$, and $52 \mathrm{~h}$. The $s y l$ gene cluster is well-expressed in both Streptomyces hosts (Fig. 4). sylC and sylD gene, which manages the extension of the core ring backbone, started the transcription process at $24 \mathrm{~h}$. $s y l B$ catalyzed the reduction of the intermediate product. During the late fermentation period, $s y l E$ encoded thioesterase to release the syringolin compounds.

\section{Biosynthesis of syringolin in heterologous Streptomyces host}

HPLC analysis showed the presence of three metabolite peaks in the culture broth of both S. coelicolor M145/ $\mathrm{P}_{\text {snpA }}$-syl and $S$. lividans $\mathrm{TK} 24 / \mathrm{P}_{\text {snpA }}$-syl mutants in

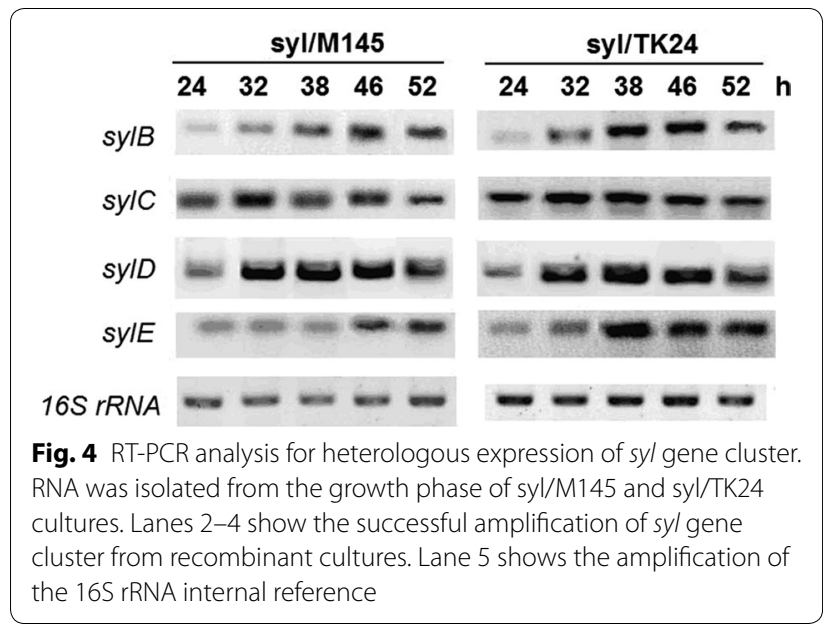
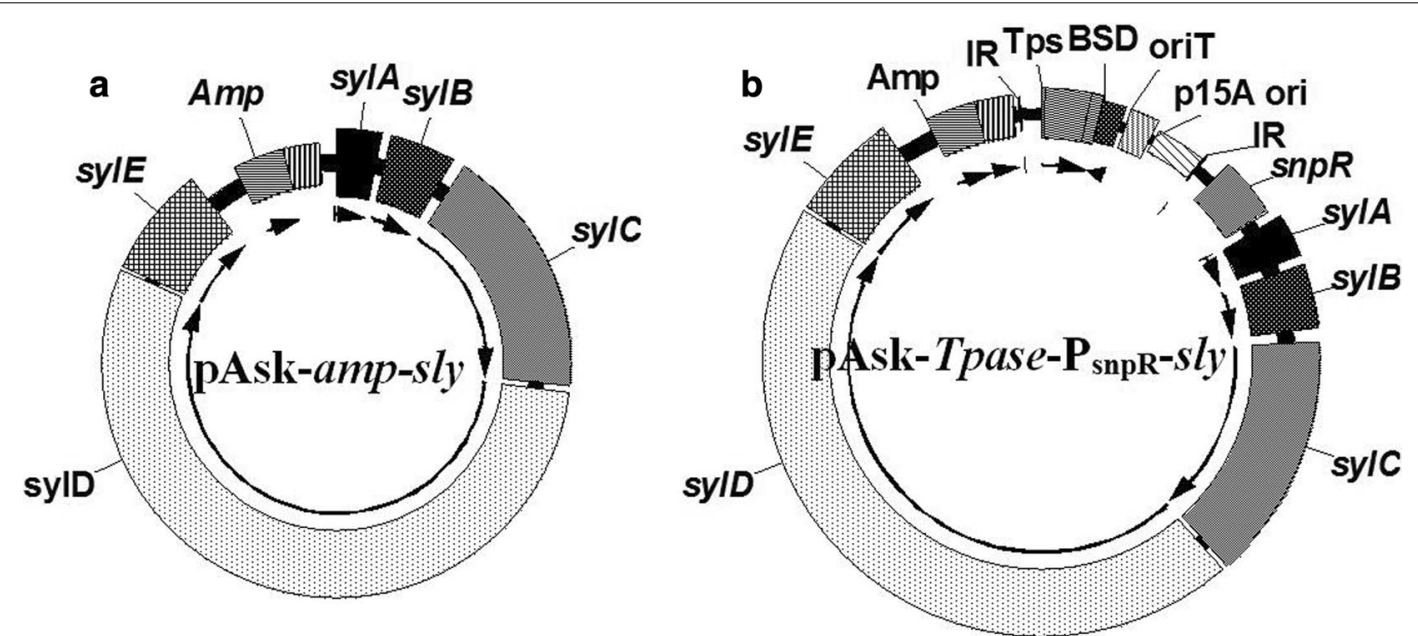

Fig. 3 Plasmids constructed for syl gene heterologous expression. Direct Cloning vector pAsk-amp-syl (a) and the resulting plasmid p15A-Tpase-syl (b). Arrows represent the direction of transcription 
comparison with the individual native strains of $S$. coelicolor M145 and S. lividans (Fig. 5a). In order to compare the yield of syringolin compounds in Streptomyces coelicolor M145 and Streptomyces lividans TK24, we measured and calculated the peak area of the major derivatives produced by the software Bruker Compass. The results showed that the production of syringolin derived compounds produced by heterologous host $S$. coelicolor M145 was about 1.3-fold that of S. lividans TK24. This 1.3-fold difference in the syringolin yield of S. lividans $\mathrm{TK} 24 / \mathrm{P}_{\text {snpA }}$-syl might have resulted from the diverse regulatory system in heterologous hosts. Overexpression of novG CstrR-like positive regulatory protein confers a higher PKS/NRPS synthesis activity to $S$. coelicolor M145 [33]. UV spectra, retention time $\left(\mathrm{R}_{t}\right)$, and MS/MS2 results in HPLC/MS comparisons revealed that all known syringolins A, B, C, D, E, and F (SylA-SylF) were detected in the extract of the two heterologous production hosts (Fig. 5b-d). The three peaks represented $\mathrm{C}_{24} \mathrm{H}_{39} \mathrm{~N}_{5} \mathrm{O}_{6}$ (syringolin $\mathrm{A} / \mathrm{B}, \mathbf{1}, \mathrm{R}_{t}=2.1 \mathrm{~min}, \mathrm{~m} / z 494$ $[M+\mathrm{H}]^{+}$), $\mathrm{C}_{26} \mathrm{H}_{43} \mathrm{~N}_{5} \mathrm{O}_{6}$ (syringolin $\mathrm{F}, 2, \mathrm{R}_{t}=4.03 \mathrm{~min}$, $m / z 522[M+\mathrm{H}]^{+}$), and $\mathrm{C}_{25} \mathrm{H}_{41} \mathrm{~N}_{5} \mathrm{O}_{6}$ (syringolin $\mathrm{C} / \mathrm{D} / \mathrm{E}$, 3, $\left.\mathrm{R}_{t}=8.37 \mathrm{~min}, m / z 508[M+\mathrm{H}]^{+}\right)$. Low-resolution ESI-MS analyses further showed that the mass of $\mathbf{1}$ is lower by 14 and 28 amu compared with that of $\mathbf{3}$ and $\mathbf{2}$, respectively. These results indicated that their real molecular weights of 1, 3, and 2 might be 493, 507, and $521 \mathrm{Da}$, respectively, suggesting the single methylene group ($\mathrm{CH}_{2}-$ ) difference, preferably at the $\mathrm{R}_{1}$ or $\mathrm{R}_{2}$ group among the compounds. The molecular formula of the syringolin derivative obtained through high-resolution EI-MS matched the predicted structure.

\section{In vitro antitumor activity of recombinant syringolin compounds}

We investigated the antitumor activity of recombinant syringolin on different tumor cell lines, and the results suggested that the extracts of the recombinant Streptomyces strains induced varying levels of cytotoxicity. All samples obtained from ethanol extraction methods were dried and resuspended in PBS, and the differences between the control and treatment groups were significantly and statistically different $(P<0.05)$, thus, confirming our results. Incubation of 4T1, B16, HeLa, and MthA cancer cells with $15,30,45$, and $60 \mu \mathrm{M}$ syringolin extracts for $24 \mathrm{~h}$ significantly reduced cell viability, as demonstrated by the reduction of MTT. Recombinant extracts showed dose-dependent cytotoxicity on all compounds. The effect of the extracts on cancer cells was evaluated (Fig. 6). Syringolin has $\mathrm{IC}_{50}$ values of $22.5,24.3,26.4$, and $35.2 \mu \mathrm{M}$ towards 4T1, HeLa, B16, and MthA, respectively. MTT analysis showed that the syringolin compound has good cytotoxicity to the above four cell lines at low concentrations (Fig. 7).

\section{In vivo antitumor activity of recombinant syringolin compounds}

We constructed two tumor models to analyze the in vivo toxicity of syringolin compounds. All mice were given 30 or $60 \mu \mathrm{M}$ dose of syringolin extract every 2 days for 10 days. BALB/c mice bearing $4 \mathrm{~T} 1$ tumor were treated with syringolin compounds through gastric lavage (Fig. 8a), intratumoral injection (Fig. 8b), or intravenous injection (Fig. 8c), and syringolin compounds had significant effect on $4 \mathrm{~T} 1$ from the latter two methods $(P<0.05)$, but had no in vivo activity from former treatment. Among the three methods, intravenous injection gave the greatest effect with $67 \%$ in vivo inhibition rate to the $4 \mathrm{~T} 1$ tumor at $30 \mu \mathrm{M}$, and extended mice mortality, resulting in delayed growth and death. Syringolin compounds by intratumoral injection could inhibit $40 \%$ tumor growth at higher concentration, and the injected mice survived under good conditions. Tumor, liver, kidney, and spleen were harvested and subjected to HE staining. Syringolin did not only increase apoptosis of $4 \mathrm{~T} 1$ cells but also protected the liver and kidney from injury (Fig. 9). Organs from control mouse models showed significant liver and kidney damage while cells from the drug-treated group were normal and did not change much. Syringolin treatment of C57BL/6 mice bearing B16 tumor by intratumoral injection also showed great in vivo antitumor activity in a dose-dependent manner at $30 \mu \mathrm{M}$ concentration with about $75 \%$ inhibition rate to B16 (Fig. 8d). B16 tumor growth almost stopped after injection of syringolin compound. Together, our results herein demonstrate the potential of syrinolin as effective anitumor agent that can treat various cancers without apparent adverse effects. 


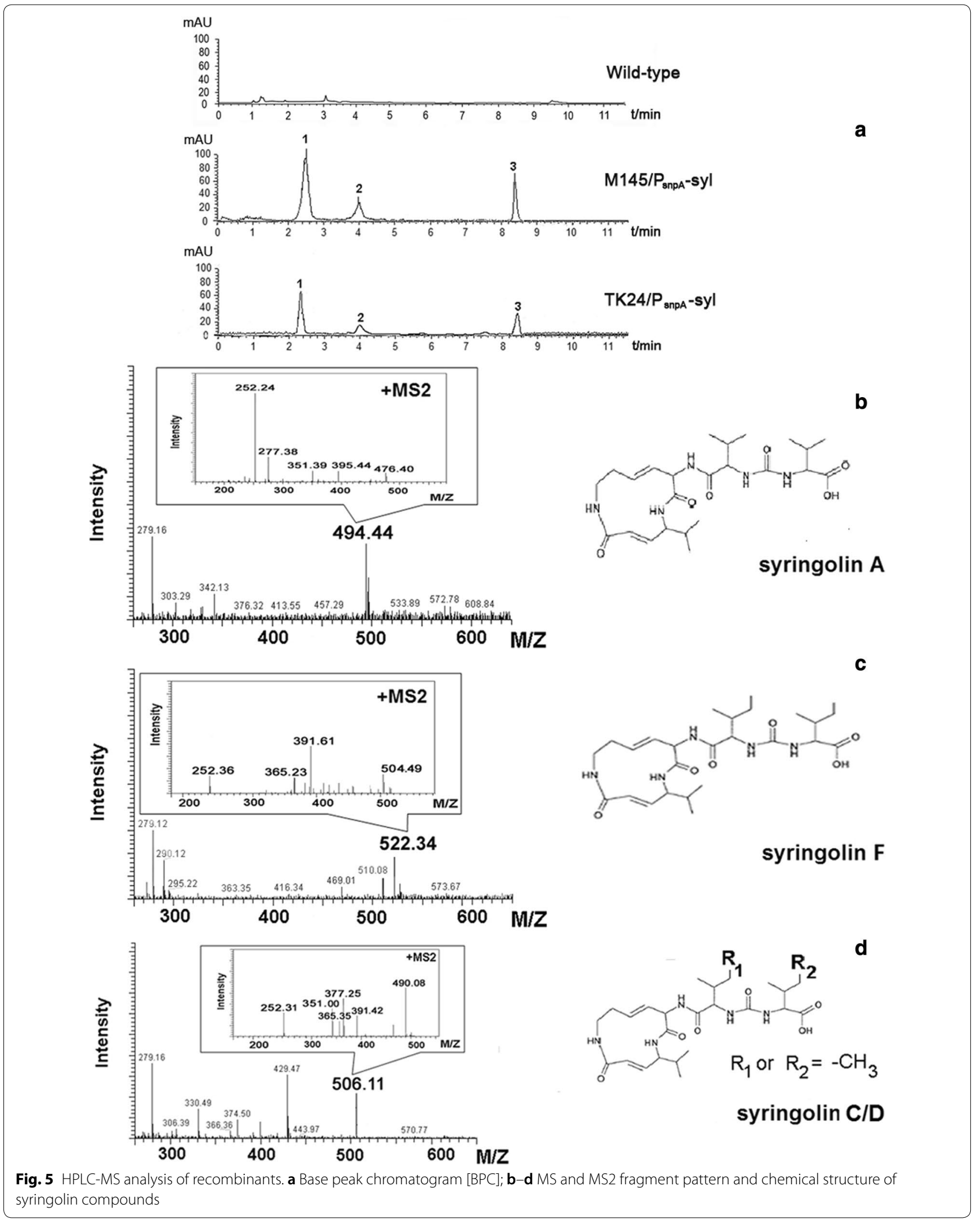




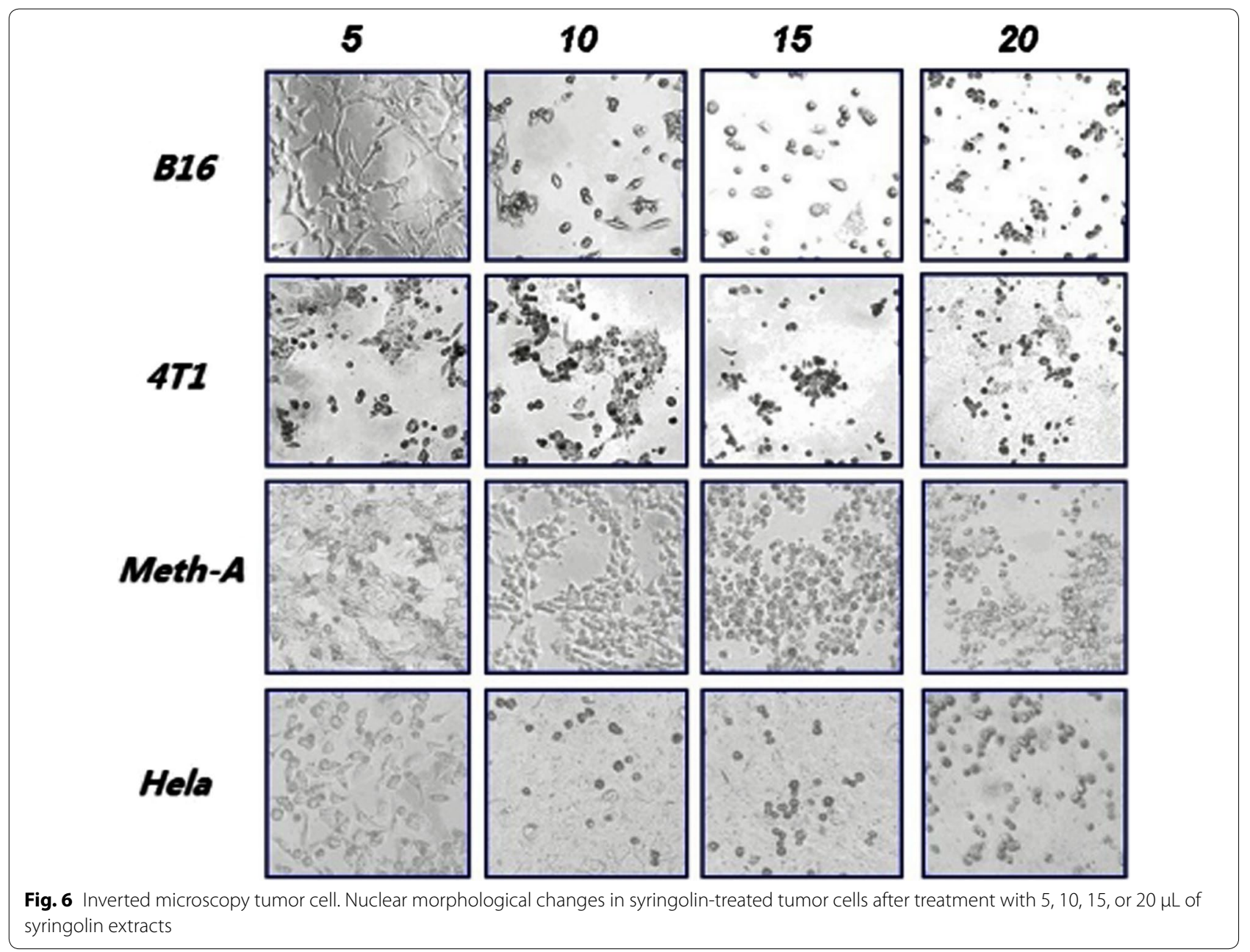

\section{Conclusions}

This paper is first to express the whole syl gene cluster in heterologous Streptomyces strains. As sylA gene activates the expression of NRPS/PKS, acquisition of intact syl gene cluster uses the LLHR straightforward strategy mediated by Red/ET recombineering. The promoter underwent exchange after one round of LLHR. The results clearly indicate that the clusters of genes are capable of encoding proteins that synthesize syringolin. In comparison with the native promoter from Pseudomonas syringae pv. syringae, the general promoter, $\mathrm{P}_{\text {snpA }}$, successfully transcribed the whole gene cluster in heterologous strains.
Large natural product biosynthetic gene clusters traditionally require reconstruction from several cosmids, which is time-consuming given the required screening process from a genomic library and subsequent cloning steps. Our direct-cloning method furnishes a general tool of reconstituting large gene clusters. When coupled with suitable heterologous expression hosts, direct cloning is effective alternative in investigating or engineering known and unknown biosynthetic pathways, from slowgrowing bacteria and poorly established genetic systems.

Subsequently, the expression of the clone in both M145 and TK 24 produce six syringolin family members, which 

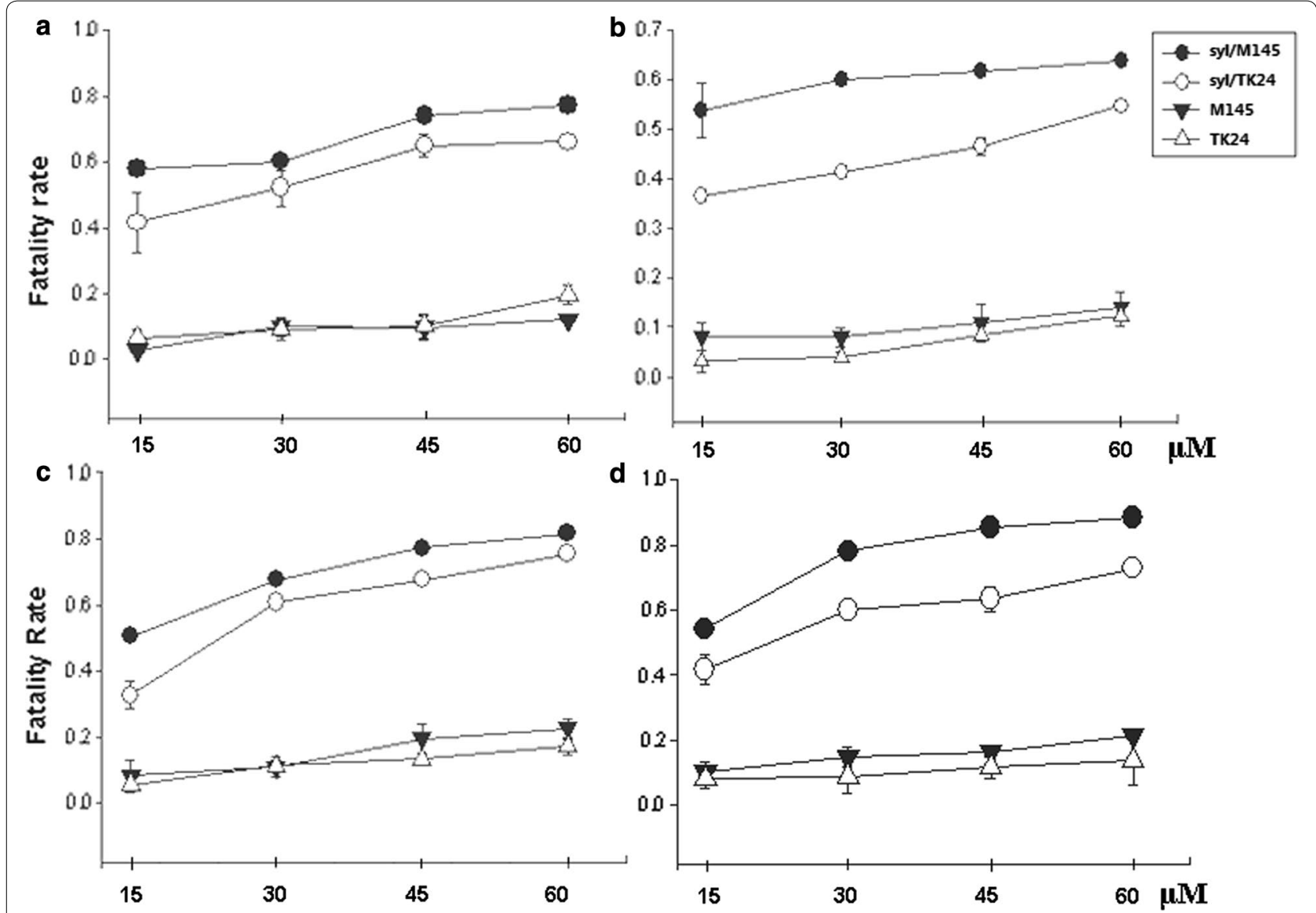

Fig. 7 MTT analysis of recombinants. Fatality rate of HeLa (a), MethA (b), B16 (c), and 4T1 (d) after $24 \mathrm{~h}$ incubation with gradient syringolin extracts

show diverse transcriptions of the syl gene regulated by synthetic promoters. Syringolin yield is about $1.5 \mathrm{mg} /$ $\mathrm{mL}$. Replacement of some strong promoters, like ermEp, $f d m \mathrm{R} 1$, or novG might regulate the gene transcription. Another possible measure in developing the production is to optimize the fermentation of heterologous stains.

Syringolin derivants demonstrated high cytotoxicity to B16, 4T1, Meth-A, and HeLa cells in vitro and to 4T1 model BALB/c mice and B16 melanotic C57BL/6 mice in vivo. SylA could preferentially target the $\beta 2$ and $\beta 5$ of the proteasome in vitro and in vivo. Structureactivity analysis revealed that the dipeptide tail of SylA contributed to $\beta 2$ specificity and identified a nonreactive SylA derivative being essential for imaging experiments. The syringoline family members showed their activities of labeling nuclear and cytoplasmic proteasomes in our research. 


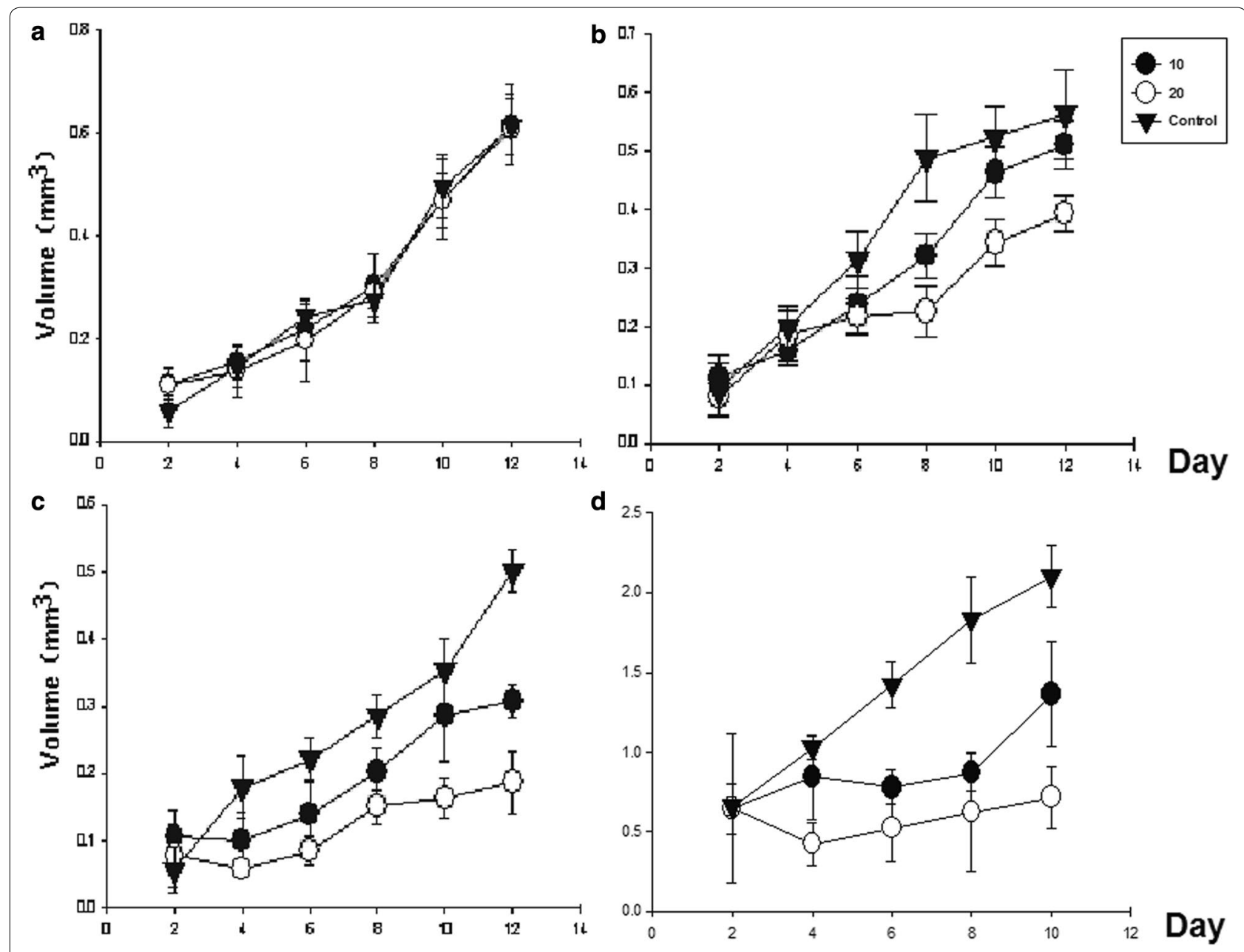

Fig. 8 In vivo antitumor activity of syringolin extracts. Treated BALB/c mice bearing 4T1 breast cancer tumor by gastric lavage (a), intratumoral injection (b), and intravenous injection (c). Syringolin-treated B16 murine melanoma model in C57BL/6 mice by intratumoral injection (d)

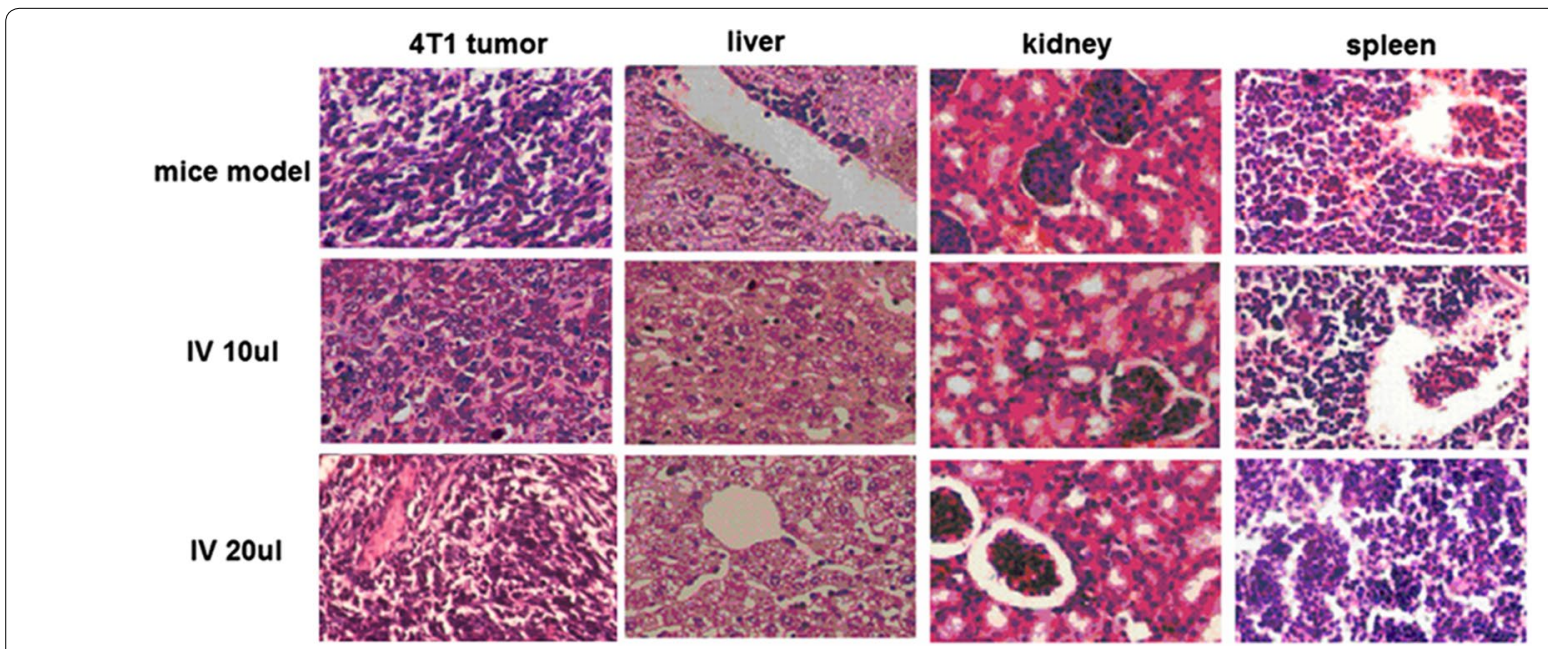

Fig. 9 HE staining of section from main organs in mice bearing 4T1 breast cancer at $\times 200$ magnification. Histological changes and apoptosis of BALB/c mice treated with 15 or $30 \mu \mathrm{M}$ dose of syringolin extract by intravenous injection 
This research provided new avenues and ideas for the discovery and production of new antitumor compounds. The antitumor effects of syringolin may be attributable to the inhibition of proteinase and cancer cell invasion, and its concrete mechanism of inducing apoptosis in cancer cells still needs further studies.

\section{Authors' contributions}

$\mathrm{FH}$ and LH designed and carried out the experiments, JLT analysed the data and prepared the manuscript. XZD and SYH carried out the HPLC analysis and LC/MS analysis of the syringolin. YMZ and YJS gave valuable suggestions in the experiments and manuscript editing. LQX supervised the research. All authors read and approved the final manuscript.

\section{Acknowledgements}

Not applicable.

\section{Competing interests}

The authors declare that they have no competing interests.

\section{Availability of data and materials}

The datasets supporting the conclusions of this article are included within the article.

\section{Consent for publication}

The authors are consent for publication.

\section{Ethics approval and consent to participate}

All animal experiments followed the National Institutes of Health Guide for the Care and Use of Laboratory Animals and were approved by the Animal Ethics Committee of Hunan Normal University.

\section{Funding}

This work was supported by the National Basic Research Program (973) of China (2012CB722301), the National High Technology Research and Development Program (863) of China (2011AA10A203), the International Cooperation Project (0102011DFA32610), and the Cooperative Innovation Center of Engineering and New Products for Developmental Biology of Hunan Province (20134486)

\section{Publisher's Note}

Springer Nature remains neutral with regard to jurisdictional claims in published maps and institutional affiliations.

Received: 30 June 2017 Accepted: 15 January 2018

Published online: 26 February 2018

\section{References}

1. Lindemann J, Arny DC, Upper CD. Use of an apparent infection threshold population of Pseudomonas syringae to predict incidence and severity of brown spot of bean. Phytopathology. 1984;74(11):1334-9.

2. Vanneste JL. The scientific, economic, and social impacts of the New Zealand outbreak of bacterial canker of Kiwifruit (Pseudomonas syringae pv. actinidiae). Ann Rev Phytopathol. 2017;55:377-99.

3. Waspi U, Blanc D, Winkler T, Ruedi P, Dudler R. Syringolin, a novel peptide elicitor from Pseudomonas syringae pv. syringae that induces resistance to Pyricularia oryzae in rice. Mol Plant Microbe Interactions. 1998:11(8):727-33.

4. Hofstetter SS, Dudnik A, Widmer H, Dudler R. Arabidopsis YELLOW STRIPELIKE7 (YSL7) and YSL8 transporters mediate uptake of Pseudomonas virulence factor syringolin A into plant cells. Mol Plant Microbe Interactions. 2013;26(11):1302

5. Wäspi U, Hassa P, Staempfli AA, Molleyres LP, Winkler T, Dudler R. Identification and structure of a family of syringolin variants: unusual cyclic peptides from Pseudomonas syringae pv. syringae that elicit defense responses in rice. Microbiol Res. 1999:154(1):89-93.

6. Reimmann C, Hofmann C, Mauch D, Dudler R. Characteriztaion of a rice gene induced by Pseudomonas syringae pv. syringae: requirement for the bacterial lemA gene function. Physiol Mol Plant Pathol. 1995;46(1):71-81.

7. Coleman CS, Rocetes JP, Park DJ, Wallick CJ, Warncramer BJ, Michel K, Dudler R, Bachmann AS. Syringolin A, a new plant elicitor from the phytopathogenic bacterium Pseudomonas syringae pv. syringae, inhibits the proliferation of neuroblastoma and ovarian cancer cells and induces apoptosis. Cell Prolif. 2006;39(6):599.

8. Ramel C, Baechler N, Hildbrand M, Meyer M, Schädeli D, Dudler R. Regulation of biosynthesis of syringolin A, a Pseudomonas syringae virulence factor targeting the host proteasome. Mol Plant Microbe Interactions. 2012;245(2):1198-208.

9. Groll M, Schellenberg B, Bachmann AS, Archer CR, Huber R, Powell TK, Lindow S, Kaiser M, Dudler R. A plant pathogen virulence factor inhibits the eukaryotic proteasome by a novel mechanism. Nature. 2008:452(7188):755.

10. Almond JB, Cohen GM. The proteasome: a novel target for cancer chemotherapy. Leukemia. 2002;16(4):433.

11. Jr PS, Shanker A. Development of proteasome inhibitors as therapeutic drugs. J Clin Cell Immunol. 2012;S5(S5):5.

12. Fu J, Bian X, Hu S, Wang H, Huang F, Seibert PM, Plaza A, Xia L, Müller R, Stewart AF. Full-length RecE enhances linear-linear homologous recombination and facilitates direct cloning for bioprospecting. Nat Biotechnol. 2012;30(5):440

13. Harms H, Kurita KL, Pan L, Wahome PG, He H, Kinghorn AD, Carter GT, Linington RG. Discovery of anabaenopeptin 679 from freshwater algal bloom material: insights into the structure-activity relationship of anabaenopeptin protease inhibitors. Bioorg Med Chem Lett. 2016:26(20):4960.

14. Harada Kl, Fujii K, Mayumi T, Hibino Y, Suzuki M, Ikai Y, Oka H. A method using L/CMS for determination of absolute configuration of constituent amino acids in peptide_-advanced Marfey's method. Tetrahedron Lett. 1995;36(9):1515-8.

15. Walther T, Renner S, Waldmann H, Arndt HD. Synthesis and structureactivity correlation of a brunsvicamide-inspired cyclopeptide collection. Chembiochem A Eur J Chem Biol. 2009:10(7):1153.

16. Grüschow S, Rackham EJ, Elkins B, Newill PL, Hill LM, Goss RJ. New pacidamycin antibiotics through precursor-directed biosynthesis. ChemBioChem. 2009;10(2):355-60

17. Ye ZW, Camus S, Augustijns P, Annaert P. Napsamycins, new Pseudomonas active antibiotics of the mureidomycin family from Streptomyces sp. HIL Y-82,11372. J Antibiot. 1994:47(5):595-8.

18. Clerc J, Groll M, Illich DJ, Bachmann AS, Huber R, Schellenberg B, Dudler $\mathrm{R}$, Kaiser M. Synthetic and structural studies on syringolin $A$ and $B$ reveal critical determinants of selectivity and potency of proteasome inhibition. Proc Natl Acad Sci USA. 2009;106(16):6507.

19. Kitahata S, Chiba T, Yoshida T, Ri M, lida S, Matsuda A, Ichikawa S. Design, synthesis, and biological activity of isosyringolin A. Org Lett. 2016:18(9):2312.

20. Chiba T, Kitahata S, Matsuda A, Ichikawa S. Design, synthesis and biological evaluation of a structurally simplified syringolin A analogues. Chem Pharm Bull. 2016;64(7):811-6.

21. Amrein H, Makart S, Granado J, Shakya R, Schneider-Pokorny J, Dudler R. Functional analysis of genes involved in the synthesis of syringolin A by Pseudomonas syringae pv. syringae B301 D-R. Mol Plant Microbe Interactions. 2004;17(1):90.

22. Imker HJ, Walsh CT, Wuest WM. SylC catalyzes ureido-bond formation during biosynthesis of the proteasome inhibitor syringolin A. J Am Chem Soc. 2009;131(51):18263-5.

23. Wuest WM, Krahn D, Kaiser M, Walsh CT. Enzymatic timing and tailoring of macrolactamization in syringolin biosynthesis. Org Lett. 2011:13(17):4518-21.

24. Yuan LZ, Rouvière PE, Larossa RA, Suh W. Chromosomal promoter replacement of the isoprenoid pathway for enhancing carotenoid production in E. coli. Metab Eng. 2006;8(1):79-90.

25. Chen TC, Wang W, Golden EB, Thomas S, Sivakumar W, Hofman FM, Louie SG, Schönthal AH. Green tea epigallocatechin gallate enhances therapeutic efficacy of temozolomide in orthotopic mouse glioblastoma models. Cancer Lett. 2011;302(2):100-8. 
26. Kieser T. Practical streptomyces genetics. Norwich: John Innes Foundation; 2000. p. 30.

27. Muyrers JP, Zhang Y, Stewart AF. Techniques: recombinogenic engineering-new options for cloning and manipulating DNA. Trends Biochem Sci. 2001;26(5):325.

28. Muyrers JP, Zhang Y, Testa G, Stewart AF. Rapid modification of bacterial artificial chromosomes by ET-recombination. Nucleic Acids Res. 1999;27(6):1555

29. Luo Y, Ding X, Xia L, Fan H, Li W, Huang S, Ying T, Sun Y. Comparative proteomic analysis of saccharopolyspora spinosa SP06081 and PR2 strains reveals the differentially expressed proteins correlated with the increase of spinosad yield. Proteome Sci. 2011;9(1):40
30. Zhang Y, Zhang Y, Xia L, Zhang X, Ding X, Yan F, Wu F. Escherichia coli Nissle 1917 targets and restrains mouse B16 melanoma and 4T1 breast tumors through expression of azurin protein. Appl Environ Microbiol. 2012;78(21):7603.

31. Zhang Y, Muyrers JP, Testa G, Stewart AF. DNA cloning by homologous recombination in Escherichia coli. Nat Biotechnol. 2000;18(12):1314.

32. Fu J, Wenzel SC, Perlova O, Wang J, Gross F, Tang Z, Yin Y, Stewart AF, Müller R, Zhang Y. Efficient transfer of two large secondary metabolite pathway gene clusters into heterologous hosts by transposition. Nucleic Acids Res. 2008;36(17):e113.

33. Borissenko L, Groll M. 20 s proteasome and its inhibitors: crystallographic knowledge for drug development. Chem Rev. 2007;38(22):687-717.

\section{Submit your next manuscript to BioMed Central and we will help you at every step:}

- We accept pre-submission inquiries

- Our selector tool helps you to find the most relevant journal

- We provide round the clock customer support

- Convenient online submission

- Thorough peer review

- Inclusion in PubMed and all major indexing services

- Maximum visibility for your research

Submit your manuscript at www.biomedcentral com/submit 